\title{
Capacity Development Services and the Demand Market in Albanian Tourism Sector
}

\author{
By Rezarta BROKAJ ${ }^{1}$
}

\begin{abstract}
:
Over the last 20 years the role of tourism has been increasingly recognized as an important development strategy, considering its importance in creating positive economical effects in worldwide level. Sustainability has become nowadays a principle of development and obviously of tourism development.

Sustainable tourism is one of the main development priorities of local, national and international authorities to ensure long term success on a global market.

One of the main reasons in sustainability of tourism development in Albania is that almost planners, operators and local community could not have created a connection through different dimensions of the sustainability.

The paper explores the need and demand for building Albania`s private sector capacity for tourism development. This study was run in the most important market actors which operate in the tourism sector in Albania, especially focusing in clients of capacity development services. Questionnaire was used to collect data from the most important tourism operators, that use these services.

The aim was to examine their views on tourism development, in an attempt to establish overall desired directions for tourism development and to suggest effective tourism strategies and policies to reinforce positive outcomes and alleviate problems resulting from previous unplanned tourism development.

According to the survey, results showed the availability of capacity building services, the links with local and international service providers, their preferred service delivery mechanisms and the barriers that exist in this market.

Hence understanding barriers of capacity development services can help to all the actors for future planning to achieve sustainable tourism development.
\end{abstract}

Keywords: capacity development, tourism operators, sustainable development, service quality.

\section{Capacity Development and its Importance in Tourism Sector}

Tourism is widely recognized as one of the largest and rapidly expanding industry sectors in the world. The business of tourism is complex and fragmented and from the time that visitors arrive in the destination, until they leave, the quality of their experience is affected by many services and experiences, including a range of public and private services, community interactions, environment and hospitality. 
Delivering excellent value will depend on many organizations working together in unity. So, destination management is a subject of growing importance as destinations compete to provide the highest quality of experience for visitors and to manage the impacts of tourism on host communities and environments.

Destination management calls for a coalition of these different interests to work towards a common goal to ensure the viability and integrity of their destination in a sustainable way.

Addressing the main challenge of integrating sustainability in tourism development, it is necessary to focus on the concept of capacity development. To compete effectively, destinations have to offer a more satisfactory experience to the consumers of tourism, an excellent value to visitors and to take advantage of new opportunities.

\section{Why is Capacity Development needed?}

The issue of capacity is critical and the scale of need is enormous, but appreciation of the problem is low. This is because:

The link between needs and supply is weak.

There is a lack of realistic funding.

There is need for support for change.

Training institutions are isolated - communications are poor.

Development of teaching materials is inefficient.

Alternative ways of capacity building are not adequately recognized.

Existing definitions of Capacity Building (mostly referred to as Capacity Development) have been described as complex and "elusive" and so far have not been used as a development objective but as a measurement to realize short-term results and reflect different perspectives.

Unfortunately, tourism development is often left to private developers and leisure service providers. Capacity building in tourism development often faced barriers and understanding barriers of capacity development in terms of types of tourism services can help to local communities for future planning to achieve sustainable tourism development. Overcoming the barriers to tourism development presents a challenge to both private sector, communities and government, and will serve to facilitate the policy making process.

Many organizations do not understand capacity building; they identify it with the training aspects.

Capacity Building is much more than training and includes the following:

Human resource development, the process of equipping individuals with the understanding, skills and access to information, knowledge and training that enables them to perform effectively.

$>\quad$ Organizational development, the elaboration of management structures, processes and procedures, not only within the organizations, but also the management of 
relationship between the different organizations and sectors: public, private and community.

$>\quad$ Institutional and legal framework development, making legal and regulatory changes to enable organizations, institutions and agencies at all levels and in all sectors to enhance their capacities.

\section{Methodology}

This paper is based on primary and secondary data. After careful consideration of literature review, primary data are gathered through a survey done with the main types of operators belonging to the tourism sector in Albania.

The market survey consisted on face to face interviews with clients of capacity development services, 77 interviews in total. These number include also interviews from local government, which in turn, is compound by local government leaders and managers as clients or purchasers of service provider, as well as semi-professionals who operate through tourism offices. The number of interviews in local and central government is 24 in total.

This study refers to the market of service clients in tourism sector, its actual development in Albania with refer to the size, actors and factors that affect its development, its importance in the development of tourism sector in Albania and the premises for long term development. In this study are included the most important market actors which operate in the tourism sector in Albania and also sustain this activity. The study has taken into consideration the group of clients of the capacity development services offered, in order to examine their views on tourism development, in an attempt to establish overall desired directions for tourism development and to suggest effective tourism strategies and policies to reinforce positive outcomes and alleviate problems resulting from previous unplanned tourism development.

The participants in this study included organizations in eight regions of the country, which responded favorably to the invitation to give feedback by completing the questionnaire. The organizations involved in this study were selected in such a way to represent the whole range of activities that they cover in the tourism sector in Albania.

Geographical coverage of the study includes the most resourced areas for developing different types of tourism, as well as most developed areas regarding the tourism sector: Vlora, Durres, Tirana, Saranda, Berat, Gjirokaster, Pogradec and Korca.

The main reason for selecting these regions is related with the considerable role of these areas in tourism development as the main tourist destinations of Albania, related to different forms of tourism development.

\section{Tourism Capacity Development Market in Albania}

Tourism is considered as a global industry and like any global industry, tourist business activities can have considerable impact on local development trends. Tourism in Albania is considered as one of the main sector of development, providing positive economic effects. 
However, there are many problems facing this sector and many possibilities to improve the existing product. This paper is designed to raise awareness on the importance of sustainable tourism and capacity development services, particularly relevant to small and medium sized enterprises in the tourism industry where there is often the misconception that their operations are too small to have significant positive or negative environmental, economic, or socio-cultural impacts. In reality, small and medium sized tourism enterprises comprise the majority of the Albanian tourism industry and collectively their business operations have an immense potential to affect the locations in which they operate.

But the capacity development market is not yet consolidated, influenced mostly by the characteristics of the potential and current target, operating time of these businesses in the market, limited financial possibilities and short term objectives.

This study serves to a better understanding of the Albanian capacity development market, focusing on the demand side.

In the demand side of this market, in the clients category are included three major client groups of tourism operators such as:

- Private tourism operators: hotel managers and/or owners, restaurants managers and/or owners, travel agencies managers, historic site personnel, considering the fact that the service provided for them is consultancy for capacity building;

- $\quad$ Public organizations: municipalities, chamber of commerce, districts, etc;

- Different associations, NPOs and NGOs, using CB services for their offered services to tourism enterprises.

The main users of $\mathrm{CB}$ services are private businesses managers and owners, reflecting the role of them in tourism development in the Albanian territory and also the structuring of this sector.

This number is followed by State agencies as another important actor of tourism development in Albania, where CB services are concentrated mainly in affording these agencies in designing plans of such development.

The main end user groups of the client services are:

- Tourists

- Community

- Tourism businesses

The final end-users of CB services are the tourists who benefit directly from the tourism services improvement deriving by such services offered to the suppliers of tourism services.

Users were asked to comment on the availability of capacity building services, their experiences with local and international service providers, and their preferred service delivery mechanisms. After the interviewing process, the available data were entered in Local Capacity Development Facility (LCDF) database and processed data were analyzed.

\section{Characteristics of clients and capacity developing services}

The tourism sector in Albania is a relatively new and the majority part of tourism businesses has been founded after 1990, when tourism sector has been identified as one 
of the main sectors important for economic development. 49,4\% of interviewed tourism units are running for over 10 years as tourism businesses or state agencies which has in their structures the tourism office This is reflected in the table below

Table 1 Years of activity of the CB clients

\begin{tabular}{|l|l|}
\hline Years of activity & Percentage \\
\hline$>=1-<=3$ & $15,6 \%$ \\
\hline$>=3-<=6$ & $13,0 \%$ \\
\hline$>=7-<=9$ & $22,1 \%$ \\
\hline$>=10$ & $49,4 \%$ \\
\hline
\end{tabular}

As shown by the figure 1 below, the majority of end - users define need and supply of capacity development services following three important ways:

- $\quad$ Existing client requests

- $\quad$ Government demands

- Merger collaboration

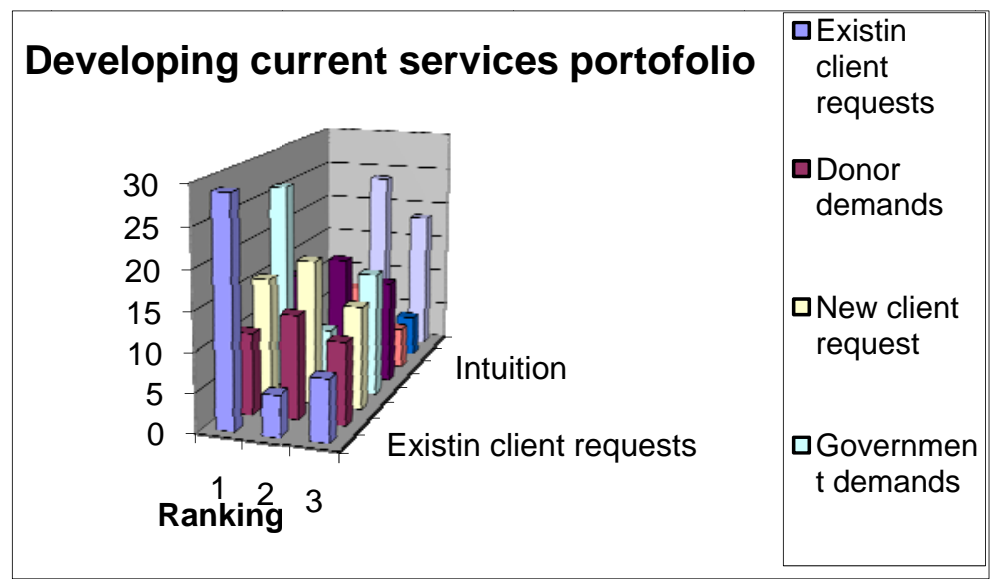

Figure 1: Developing current services portfolio

By the point of view of the clients of the $\mathrm{CB}$ services the majority of the clients interviewed pointed out that the factors that influence the selection of $\mathrm{CB}$ services ranked as the most important are:

- $\quad$ Certainty of our own needs 50,6\%

- $\quad$ Our time availability $27,3 \%$

- $\quad$ Quality of CB services and knowledge of them 20,8\% 


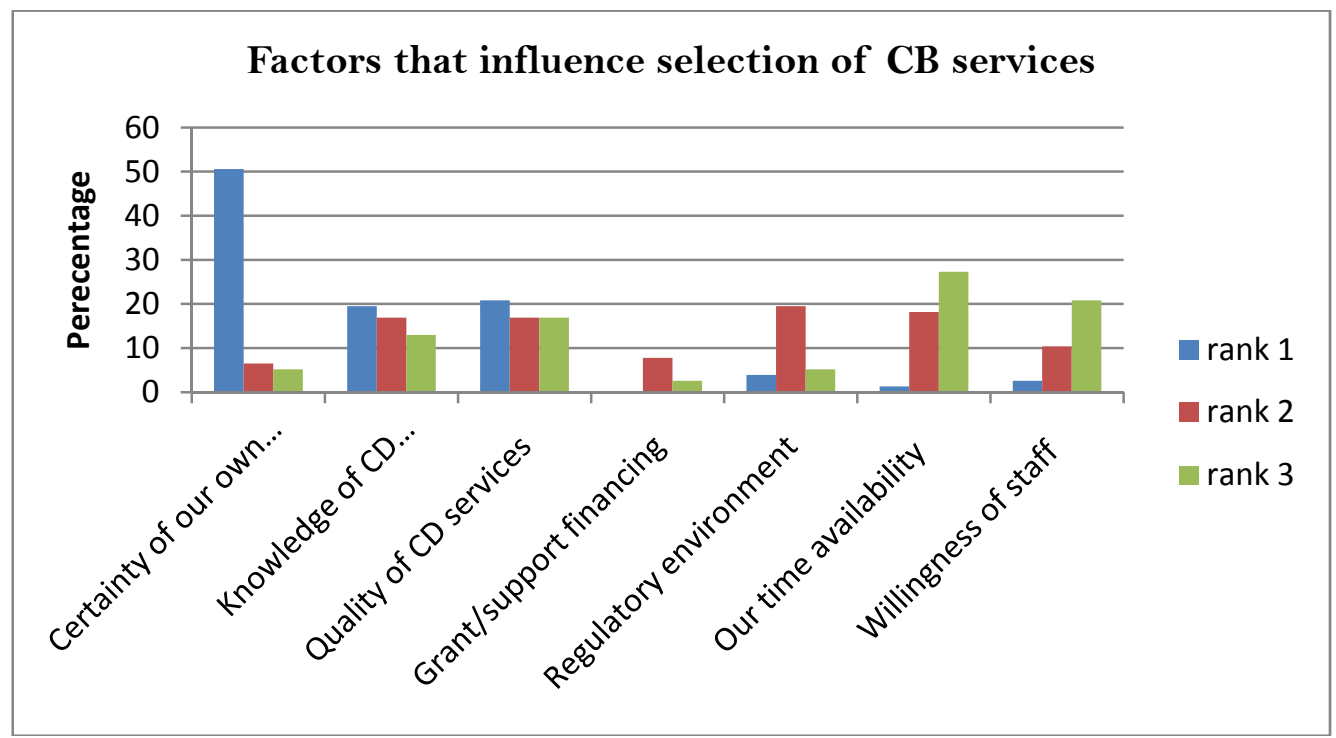

Figure 2: Factors that influence selection of $C B$ services

These factors make evidence of the fact that in Albania this market is in a very first stage and it is not influenced in the right way. The majority of the clients consider the most their needs without having a right accordance with the whole sector and the environment in which this development take part.

It depends on the type of organization that present demand for the LCBs in their categorization in each of the groups. From the results of this project we note that the majority of the tourism operators are interested in different kinds of general and specific services offered by them.

So, what is considered very important for the tourism businesses located in Albania is the education and training process that actually is furnished by the schools, universities, NPOs and NGOs as part of development projects financed by public institutions and other forms of financing.

This is a process made not only with the actual and future professionals but also with the residents of different potential tourist areas to raise the awareness for the development of this sector in their living area, especially for the development of the familiar tourism, which has great possibilities of development generally in all the Albanian territory, because of its agricultural nature.

In evaluating mechanisms to benefit the local community, tourism operators should be focused in community based tourism, as a form of sustainable tourism and a good option for providing many jobs, since tourism is labor intensive and accordingly have low entry barriers.

It is important that tourism companies work to build the capacity of local producers and products and incorporate these items in their day-to-day business operations.

Another kind of service, performed the most by LCBs suppliers, is also strategic tourism planning that differs in the services performs for private operators and public ones. 
So, specific services concerning the strategic planning of hotels, restaurants, etc relate the most to the projection of the product offered by them to the tourist market, taking in consideration location, forms of tourism developed the most in their location area and the needs of the market.

Relating to the public organizations strategic planning refers to the territorial developing strategies that includes also projection of the tourism products offered by that area and capacity building of it related to the equilibrium between supply and demand for different forms of tourism developed in the concerned area.

This is very important for the sustainable development of tourism, because it create the possibility to conserve tourism resources for the future.

Territorial and urban planning services refers the most to the landscape architects, which perform the most services for private tourism operators in the furnishing of their ambience that must be conform to the types of services offered by these operators.

An important consideration must be said regarding this, because in Albania there is a lack of architects specialized for tourism investments influencing the quality of their projects. In fact, in the majority of tourism businesses interviewed, it was noted that there is not any originality in the tourism investments made in the Albanian territory creating problems, especially for the authenticity of the tourism offer.

\section{Viewpoints over quality}

Another important topic related to sustainable development is the quality of product. The table below presents the most used elements to control quality.

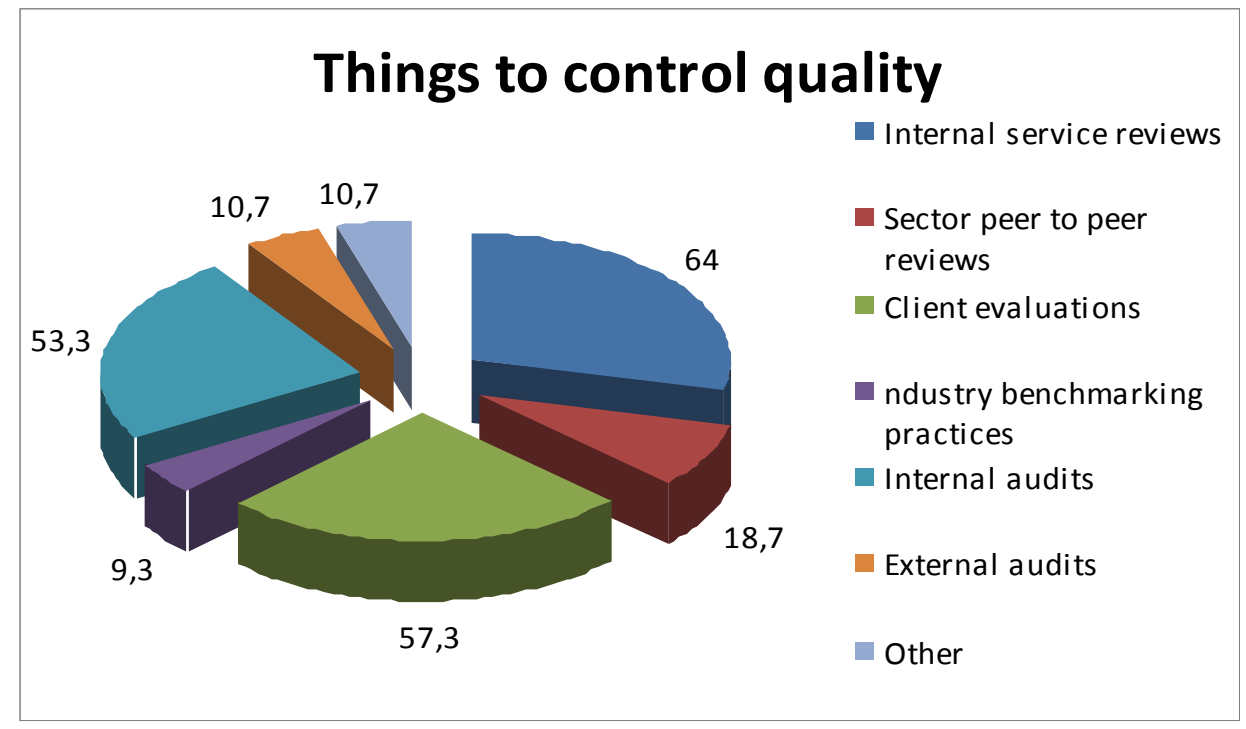

Figure 3 : Specific things to do to control quality

In fig 3, the elements used to control quality can also be drivers for service development. The most elements used are Internal service reviews and client evaluations, respectively mentioned in 64 and 57,3 percent of the cases. Internal audits also can impact quality control, but in 53,3 percent of the cases. Less important are factors as peer-to-peer reviews or external audits, factors which represent competition and professional controls 
about quality. This figures reinforce the problems with competition and standards of quality.

There are some quality standards defined by the service provider. The most important element is considered sustainability, which mean the capacity building must have a long term impact on the organization activities. This is argued from the analyses of the most needed CB services, especially aspects related with trainings, management, finance and marketing activities.

Materials/documentation and content are the two most important following factors in determining quality of their services. Another important element determining the quality of $\mathrm{CB}$ include service provider skills, which are especially important for the tourism service sector. Well trained, experienced and experts of the field are the main characteristics of the CB suppliers that will affect creating a supply-demand balance.

Urgency of need, which means providing capacity building at the time the clients need is no less important when we discuss the service quality. In the market competition, offering the right service, at the right time may be used as a competitive advantage.

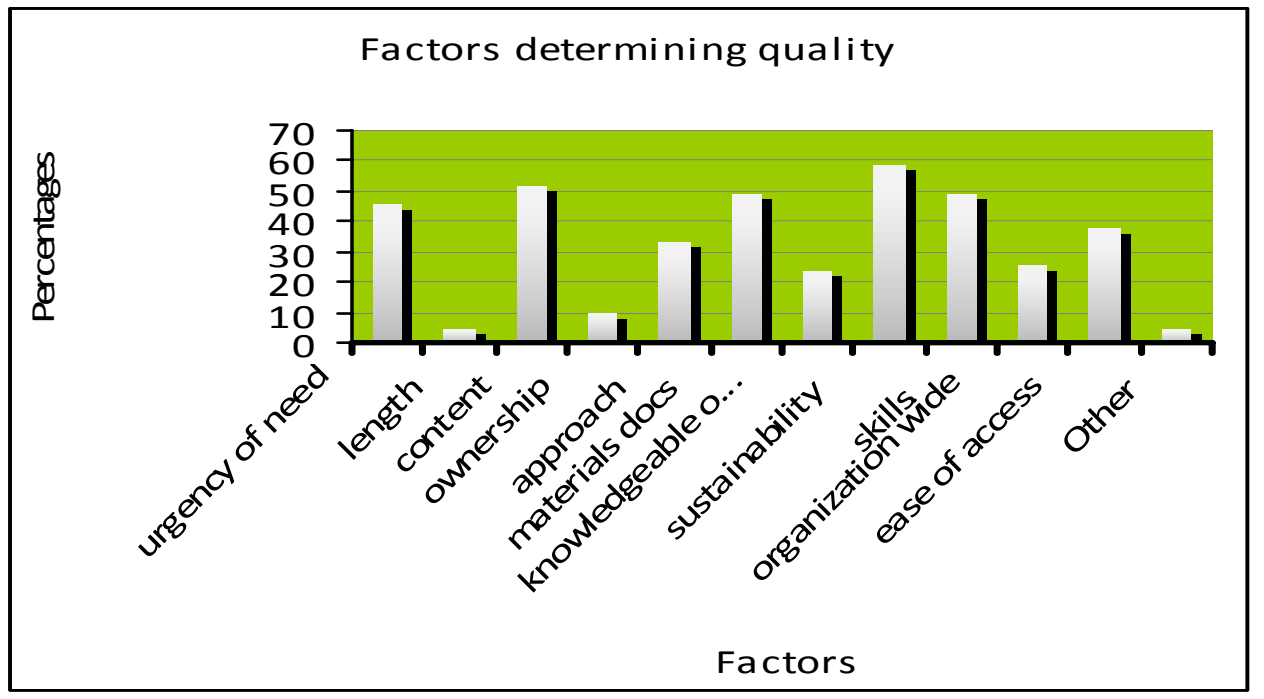

Fig 4: Factors defining quality

\section{Conclusions and Reccomandations}

It is important to note that sustainable tourism is a continuous process and it requires constant monitoring of impacts and introducing the necessary preventive and/or corrective measures whenever necessary.

The needs for capacity building are always changing. There are no ready solutions, and any program must be appropriate for the local situation and organization.

In the current stage of tourism development in Albania, access to new resources may serve as a important key success. A rich offer, market segmentation, qualified and experienced personal, innovation in services and product and membership in hotel chains are also important key success factors for clients. 
It is very important building a strong understanding of the principles of sustainability and guiding tourism enterprises in developing initial action plans to introduce sustainable practices into their company products/business operations.

So, the internal environment of their organizations is very important, not because of the great development they have achieved but by the fact that business environment in Albania and the influence of this external environment with a regulatory influence is not considerable, creating great problems for the tourism sector.

The most services used by clients are general in nature. Specific services are not as vast as they should be by both parties. This is partly because of the nature of tourism sector, which development is more dependent from government policies and strategies, but also because the investments in all capacities in tourism enterprises is due to entrepreneurship, without real combined efforts by all actors and stakeholders. Problems arise also with buyer knowledge of the market and forms of communication that focus more on personal contacts.

The priority of tourism development in order to achieve sustainability should be focused on:

$\begin{array}{ll}> & \text { Strategic long - term planning } \\ > & \text { Fuman resources development } \\ > & \text { Effective and strong government institutions } \\ > & \text { Participation of local community in policy development } \\ & \text { High level of cooperation }\end{array}$

One challenge for companies in Albania looking to better manage their offer and to provide a competitive position in the market is to identify the best strategies to link their product to consumers needs.

\section{References}

Barriers of Community Capacity Building in Types of Tourism Activities - Fariborz Aref \& Sarjit S Gill Marsland Press Journal of American Science 2010

Building community Capacity for indigenous sustainable tourism development - John Colton, Acadia University

2007 World Tourism Organization - ISBN 978-92-844-1243-3A Practical Guide to Tourism Destination Management

Building Nepal`s Private Sector Capacity for Sustainable Tourism Operations, 2008, A collection of best practices resulting business benefits

Building Tourism Excellence at the Community Level: Capacity Building for Community-Based Entrepreneurs in Uganda, Raymond Victurine (2000), Journal of Travel Research

Building Tourism Excellence at the Community Level: Capacity Building for Community-Based Entrepreneurs in Uganda, Christina Koutra and Jon Edwards (2012), Journal of Travel Research

World Tourism Organisation, 2008. UNWTO World Tourism Barometer. Madrid: World Tourism Organisation The Global Development Research Center (GDRC) 2009. Documents and Reports on Sustainable Tourism

Shunnaq, M., Schwab, W.A., and Reid, M., 2007. Community Development Using a Sustainable Tourism Strategy: a Case Study of the Jordan River. International journal of tourism research

Ritchie, J. R., and Brent., 2005. Competitive Destination: A Sustainable Tourism Perspective 
